\title{
Pathway-based analysis of rare and common variants to test for association with blood pressure
}

\author{
Huda Alsulami ${ }^{1,2,3}$, Xiaofeng Liư ${ }^{3}$, Joseph Beyene ${ }^{2,3^{*}}$ \\ From Genetic Analysis Workshop 18 \\ Stevenson, WA, USA. 13-17 October 2012
}

\begin{abstract}
Our goal is to test the effect of both rare and common variants in a blood pressure study. We use a pathwaybased approach, gene-set enrichment analysis, to search for related genes affecting 4 phenotypes: systolic blood pressure, diastolic blood pressure, the difference between each of them and mean arterial pressure, which is a weighted linear combination of systolic and diastolic blood pressure. Using the real Genetic Analysis Workshop 18 data, we consider both rare and common variants in our analysis and incorporate other covariates by using a recently proposed test statistic.

Our study identified a commonly enriched gene set/pathway for the two derived phenotypes we analyzed: the difference between systolic and diastolic blood pressure and mean arterial pressure, but none is identified with the individual blood pressure phenotypes. The gene CD47, in the enriched gene pathway/set, was reported in previous studies to be related to blood pressure.

The findings are not surprising because the sample size we use in our analysis is small, and hence power to detect small but important effects is likely inadequate.
\end{abstract}

\section{Background}

Worldwide, hypertension contributes to more than 10 million deaths and it affects one-third of the adult population per year [1]. It was predicted that the incidence of hypertension among adults in 2025 will reach 1.56 billion and contribute to approximately $54 \%$ of stroke and $47 \%$ of ischemic heart disease. Furthermore, it is a major risk factor for cardiovascular disease [2]. Several factors, including genetic, environmental, and demographic factors, play a major role in the development of hypertension. However, it is believed that $30 \%$ to $60 \%$ of the variability in blood pressure (BP) is inherited [1].

Many genome-wide association studies (GWAS) have been conducted to identify single-nucleotide polymorphism (SNPs) that are significantly associated with systolic blood pressure (SBP), diastolic blood pressure (DBP), and/or hypertension.

\footnotetext{
* Correspondence: beyene@mcmaster.ca

${ }^{2}$ Mathematics and Statistics Department, McMaster University, Hamilton, Ontario, Canada

Full list of author information is available at the end of the article
}

Meta-analysis findings of the Global BPgen (Global Blood Pressure Genetics) consortium $(n=34,433)$ and CHARGE (The Cohorts for Heart and Aging Research in Genome Epidemiology) consortium $(\mathrm{n}=29,136)$ based on populations of European ancestry identified 4 loci significantly associated with SBP (ATP2B1, CYP17A1, PLEKHA7, SH2B3), 6 associated with DBP (ATP2B1, CACNB2, CSK-ULK3, SH2B3, TBX3-TBX5, ULK4), and 1 associated with hypertension (ATP2B1) [1]. However, a genome-wide association study by Adeyemo et al [3] based on a population of African Americans $(\mathrm{n}=1017)$ identified significant loci for SBP in or near the genes PMS1, SLC24A4, YWHA7, IPO7, and $C A C A N A 1 H$, while no significant loci were discovered to be associated with DBP or hypertension.

Unlike single-gene analysis, pathway-based approaches consider multiple genes that are related together within gene sets/pathways; these pathways are predefined gene sets from biological databases. The aim of pathway-based approaches is to assess the significance of these sets/pathways by evaluating the enrichment of genes within a pathway at the top of a list of ranked genes [4-6]. Pathway-based 
analysis was originally applied to gene expression data; however, it has also been applied to GWAS data [4]. In this paper, we use a pathway-based approach based on Gene Set Enrichment Analysis (GSEA) [4]. We consider both rare and common variants and incorporate other covariates, including age, gender, use of antihypertensive medications, and smoking status. Our main focus is to test the effects of both rare and common variants on SBP, DBP, the difference between them (SBP-DBP), and mean arterial pressure (defined as MAP $=[2 / 3 \mathrm{DBP}]+[1 / 3 \mathrm{SBP}])$ by applying GSEA.

\section{Methods}

\section{Phenotype and covariate data description}

This data set was provided by the organizers of the Genetic Analysis Workshop 18 (GAW18). From this data set, we considered the 157 unrelated individuals with their phenotypes. Phenotypes were taken at 4 time points and included systolic and DBP measurements and hypertension. The following covariates were also provided: age, smoking status, antihypertensive medications usage, and gender. In our analysis, we used the baseline data; among the 157 unrelated individuals we had 129 individuals who had been genotyped. Table 1 summarizes the data.

\section{Genotype data description}

Genotype data were provided only for odd-numbered autosomal chromosomes. In this paper, we focus on variants on chromosome 3 (as suggested by the GAW18 organizers to allow comparisons of findings with other GAW18 contributions).

\section{Pathway-based analysis}

We considered 4 phenotypes of interest SBP, DBP, SBP$\mathrm{DBP}$, and MAP and performed pathway-based analysis. We followed the following steps [4,5]:

\section{Step 1: Mapping SNPs to genes}

Among the 1,215,296 SNPs on chromosome three, 523,147 SNPs were mapped to 1224 known genes using NBCI2R.

\begin{tabular}{lc}
$\begin{array}{l}\text { Table } \mathbf{1} \text { Descriptive statistics for phenotypes and } \\
\text { covariates at baseline for } \mathbf{1 2 9} \text { unrelated individuals }\end{array}$ \\
\hline Variable & Summary measure* \\
\hline SBP & $128.4 \pm 21.8$ \\
DBP & $71.8 \pm 9.2$ \\
MAP & $90.7 \pm 11.6$ \\
SBP-DBP & $56.6 \pm 19$ \\
Hypertension (Yes, No) & $129(29.5)$ \\
Age & $52.9 \pm 15.6$ \\
Sex (Female) & $129(60.5)$ \\
Medications use (Yes, No) & $129(20.2)$ \\
Smoking status (Yes, No) & $129(24.8)$ \\
\hline
\end{tabular}

*Mean \pm SD for continuous variables; $\mathrm{n}(\%)$ for categorical variables.

\section{Step 2: Obtaining test statistics for genes}

We considered both rare and common variants and other covariates (age, smoking status, medications use, and gender) to assign a test statistic for each gene. VWTOW (variable weight test for testing the effect of an optimally weighted combination of variants) [8] was used to construct test statistics and their $p$ values. Assume that we have $n$ individuals who have been genotyped at $M$ variants and is the trait of interest for the $i^{\text {th }}$ individual. Each individual has a genotypic score ${ }^{\mathrm{T}}$ where $\{0,1,2\}$ denotes the number of copies of the minor allele for the $m^{\text {th }}$ variant of the $i^{\text {th }}$ individual. We used a minor allele frequency (MAF) threshold of less than $1 \%$ to define rare variants. To test the effect of the optimally weighted combination (TOW) of variants $x_{i}^{0}=\sum_{m=1}^{M} w_{m}^{0} x_{i m}$, we used the statistic:

$$
T_{T}=\sum_{i=1}^{n}\left(y_{i}-\bar{y}\right)\left(x_{i}^{0}-\bar{x}^{0}\right)
$$

where $w_{m}^{0}=\sum_{i=1}^{n}\left(y_{i}-\bar{y}\right)\left(x_{i m}-\bar{x}_{m}\right) / \sum_{i=1}^{n}\left(x_{i m}-\bar{x}_{m}\right)^{2}$ are the optimal weights.

To test the effect of both rare and common variants, we applied TOW to each of them separately; $T_{r}$ and $T_{c}$ denote these statistics, respectively. Then we used the test statistic of VW-TOW:

$$
T_{V W_{-} T}=\min _{0 \leq \lambda \leq 1} p_{\lambda}
$$

where $p_{\lambda}$ is the $p$ value of the test $T_{\lambda}$ and $T_{\lambda}=\lambda \frac{T_{r}}{\sqrt{\operatorname{var}\left(T_{r}\right)}}+(1-\lambda) \frac{T_{c}}{\sqrt{\operatorname{var}\left(T_{c}\right)}}$. To evaluate the $p$ value of $T_{V W_{-} T}$, we used the permutation test.

We incorporated the other covariates $\left(z_{i 1}, \ldots, z_{i p}\right)^{\mathrm{T}}$ for each individual $i$, by adjusting $y_{i}$ and $x_{i m}$ using linear regression:

$$
\begin{aligned}
& y_{i}=\alpha_{0}+\alpha_{1} z_{i 1}+\ldots+\alpha_{p} z_{i p}+\epsilon_{i} \text { and } \\
& x_{i m}=\alpha_{0 m}+\alpha_{1 m} z_{i 1}+\ldots+\alpha_{p m} z_{i p}+\tau_{i m}
\end{aligned}
$$

And by using the residuals $\tilde{y}_{i}$ and $\tilde{x}_{i m}$, the following TOW and VW-TOW were used:

$$
\begin{aligned}
& T_{\text {TOW }}=T_{T \mid y_{i}=\tilde{y}_{i}, x_{i m}=\tilde{x}_{i m}} \text { and } \\
& T_{V W \_T O W}=T_{V W-T \mid y_{i}=\tilde{y}_{i}, x_{i m}=\tilde{x}_{i m}}
\end{aligned}
$$

\section{Step 3: Pathway analysis}

We ranked all the genes $(\mathrm{N})$, that had $p$ values and test statistics, based on their statistical significance from the smallest to the largest $p$ values. From step 2 , we had $(\mathrm{N}=$ $1187)$ genes for SBP and DBP and $(\mathrm{N}=1188)$ genes for SBP-DBP and MAP. Using the GSEA method [6], we evaluated the significance of predefined gene sets/pathways obtained from online pathway databases (The Molecular 
Signatures Database) [9]. We used the c2 curated gene sets (v3.1), which are compiled from online pathway databases, publications in PubMed, and knowledge of domain experts [9], which consisted of 4850 gene sets, but we only considered 3638 sets that had at least 1 gene from chromosome 3 and at least 10 genes in total. Of the 3638 pathways, $69.1 \%$ have between 1 and 5 genes on chromosome 3 , while $24.1 \%$ of the pathways have between 6 and 20 genes and $6.8 \%$ have between 21 and 140 genes on the same chromosome. Then we calculated the enrichment score (ES) for each set/pathway using a weighted KolmogorovSmirnov-like running-sum statistic. This statistic describes the overrepresentation of the genes within the set at the top of the ranked genes. We then adjusted for different sizes of genes using 1000 gene-based permutations $(\pi)$ and calculated the normalized enrichment score (NES) for each set $(S)$.

$$
\operatorname{NES}(S)=\frac{\operatorname{Actual}(E S(S))}{\text { mean }(E S(S, \pi))}
$$

To estimate the significance level of NES for each set/ pathway, we used the gene-based permutation approach to obtain the empirical $p$ values of the NES. We used 1000 gene-set permutations and then we considered the set/pathway to be significantly enriched if its false discovery rate (FDR) $q$ value is less than 0.05 . We implemented the analysis using the GSEApreranked tool included in the GSEA software [6,7].

\section{Results}

Considering common and rare variants from chromosome 3 with other covariates, and applying GSEA to our data, we ranked the top 10 gene sets/pathways based on their FDR $q$ values for each phenotype. These ranked genes are listed in Tables 2, 3, 4, and 5 for MAP, (SBP$\mathrm{DBP}), \mathrm{SBP}$, and DBP phenotypes, respectively. We found that no gene sets were enriched when we considered SBP or DBP. However, we were able to identify 1 significant enriched gene pathway from c2 curated gene sets (Table 2) with MAP. Interestingly, the same pathway was declared to be significantly enriched with the difference between SBP and DBP phenotype (Table 3). We identified the same gene pathway (Koyama_Sema3B_Targets_DN) in both phenotypes, and this

Table 2 The top 10 gene sets/pathways from c2 curated gene sets ranked by FDR $q$ values for MAP

\begin{tabular}{lcccc}
\hline Pathway name & No. genes* & ES & NES & FDR $\boldsymbol{q}$ value \\
\hline KOYAMA_SEMA3B_TARGETS_DN & 18 & 0.611 & 2.226 & 0.040 \\
\hline HUANG_GATA2_TARGETS_UP & 11 & 0.559 & 1.769 \\
\hline ONO_FOXP3_TARGETS_DN & 5 & 0.724 & 1.757 & 0.903 \\
\hline BENPORATH_ES_2 & 4 & 0.859 & 1.938 & 0.929 \\
\hline CARDOSO_RESPONSE_TO_GAMMA_RADIATION_AND_3AB & 3 & 0.865 & 1.770 \\
\hline ZHANG_TLX_TARGETS_6OHR_UP & 22 & 0.423 & 1.625 & 0.967 \\
\hline LAIHO_COLORECTAL_CANCER_SERRATED_DN & 1 & 0.891 & 1.202 & 0.981 \\
\hline PID_INTEGRIN2_PATHWAY & 1 & 0.915 & 1.203 & 0.992 \\
\hline LIU_TARGETS_OF_VMYB_VS_CMYB_DN & 5 & 0.501 & 1.203 & 0.992 \\
\hline LIM_MAMMARY_STEM_CELL_DN & 21 & 0.317 & 1.203 & 0.992 \\
\hline
\end{tabular}

*Number of genes on chromosome 3 .

Table 3 The top 10 gene sets/pathways from c2 curated gene sets ranked by FDR q-values for the difference between SBP and DBP

\begin{tabular}{|c|c|c|c|c|}
\hline Pathway name & No. genes* & ES & NES & FDR $q$ value \\
\hline KOYAMA_SEMA3B_TARGETS_DN & 18 & 0.614 & 2.227 & 0.042 \\
\hline ZHAN_MULTIPLE_MYELOMA_CD1_AND_CD2_UP & 4 & 0.830 & 1.867 & 0.822 \\
\hline TURASHVILI_BREAST_LOBULAR_CARCINOMA_VS_LOBULAR_NORMAL_UP & 7 & 0.691 & 1.888 & 0.823 \\
\hline BREDEMEYER_RAG_SIGNALING_NOT_VIA_ATM_DN & 4 & 0.811 & 1.844 & 0.871 \\
\hline LI_INDUCED_T_TO_NATURAL_KILLER_DN & 7 & 0.693 & 1.907 & 0.892 \\
\hline BENPORATH_ES_2 & 4 & 0.858 & 1.941 & 0.917 \\
\hline TONKS_TARGETS_OF_RUNX1_RUNX1T1_FUSION_SUSTAINED_IN_GRANULOCYTE_UP & 3 & 0.869 & 1.762 & 0.958 \\
\hline CHANG_CORE_SERUM_RESPONSE_DN & 21 & 0.290 & 1.091 & 0.976 \\
\hline WONG_ENDMETRIUM_CANCER_UP & 2 & 0.625 & 1.082 & 0.976 \\
\hline NOUZOVA_TRETINOIN_AND_H4_ACETYLATION & 18 & 0.299 & 1.090 & 0.976 \\
\hline
\end{tabular}

*Number of genes on chromosome 3. 
Table 4 The top 10 gene sets/pathways from c2 curated gene sets ranked by FDR $q$ values for SBP

\begin{tabular}{|c|c|c|c|c|}
\hline Pathway name & No. genes* & ES & NES & FDR $q$ value \\
\hline GOTTWEIN_TARGETS_OF_KSHV_MIR_K12_11 & 6 & 0.588 & 1.554 & 0.623 \\
\hline SMIRNOV_RESPONSE_TO_IR_6HR_UP & 6 & 0.583 & 1.554 & 0.628 \\
\hline PID_SHP2_PATHWAY & 3 & 0.738 & 1.542 & 0.629 \\
\hline JIANG_VHL_TARGETS & 6 & 0.588 & 1.550 & 0.630 \\
\hline SHEDDEN_LUNG_CANCER_GOOD_SURVIVAL_A12 & 18 & 0.408 & 1.555 & 0.631 \\
\hline PLASARI_TGFB1_SIGNALING_VIA_NFIC_10HR_UP & 5 & 0.628 & 1.543 & 0.632 \\
\hline CHEN_PDGF_TARGETS & 4 & 0.668 & 1.545 & 0.632 \\
\hline PID_IGF1_PATHWAY & 3 & 0.759 & 1.542 & 0.633 \\
\hline NAKAMURA_TUMOR_ZONE_PERIPHERAL_VS_CENTRAL_DN & 32 & 0.349 & 1.555 & 0.633 \\
\hline PID_BCR_5PATHWAY & 3 & 0.764 & 1.557 & 0.633 \\
\hline
\end{tabular}

*Number of genes on chromosome 3.

Table 5 The top 10 gene sets/pathways from c2 curated gene sets ranked by FDR $q$ values for DBP

\begin{tabular}{|c|c|c|c|c|}
\hline Pathway name & No. genes* & ES & NES & $\begin{array}{c}\text { FDR } \\
q \text { value }\end{array}$ \\
\hline PHONG_TNF_RESPONSE_VIA_P38_COMPLETE & 13 & 0.583 & 1.743 & 0.580 \\
\hline DELYS_THYROID_CANCER_DN & 11 & 0.612 & 1.748 & 0.599 \\
\hline CORRE_MULTIPLE_MYELOMA_DN & 3 & 0.897 & 1.733 & 0.603 \\
\hline SHEPARD_BMYB_MORPHOLINO_UP & 10 & 0.609 & 1.712 & 0.617 \\
\hline LI_INDUCED_T_TO_NATURAL_KILLER_UP & 17 & 0.537 & 1.724 & 0.617 \\
\hline WILCOX_PRESPONSE_TO_ROGESTERONE_UP & 6 & 0.705 & 1.700 & 0.621 \\
\hline WAMUNYOKOLI_OVARIAN_CANCER_LMP_DN & 13 & 0.562 & 1.674 & 0.632 \\
\hline KEGG_RENIN_ANGIOTENSIN_SYSTEM & 3 & 0.932 & 1.761 & 0.632 \\
\hline OSWALD_HEMATOPOIETIC_STEM_CELL_IN_COLLAGEN_GEL_DN & 11 & 0.605 & 1.751 & 0.633 \\
\hline REACTOME_POST_TRANSLATIONAL_PROTEIN_MODIFICATION & 16 & 0.535 & 1.685 & 0.644 \\
\hline
\end{tabular}

*Number of genes on chromosome 3

pathway had been shown to be related to different kinds of cancer $[10,11]$. In this pathway, 12 of 18 genes on chromosome 3 contributed to the enrichment score and the most interesting gene in this pathway is CD47. Several articles $[12,13]$ reported that this gene regulates BP.

Because our pathway-based analysis is restricted to genes on chromosome 3 , the number of pathways used for analysis exceeded the number of genes, which can have important implications in interpreting our findings. The results from our analyses should be interpreted cautiously.

\section{Conclusions}

Gene-set enrichment analysis considers multiple genes that are related biologically. In our data, we identified 1 identical enriched gene set/pathway with the MAP and the difference between SBP and DBP. The gene CD47 in this pathway was reported previously to be related to BP.

Our analysis included only 129 unrelated individuals. Sample size plays a major role in identifying enriched gene sets/pathways, which could explain the lack of significant pathways in our analysis. Future studies can be done by applying GSEA on large family-based data where incorporating both rare and common variants, taking into account the correlations between individuals and increasing the sample size, may lead to new discoveries.

\section{Competing interests}

The authors declare that they have no competing interests.

\section{Authors' contributions}

HA designed the overall study; HA and XFL performed all of the data analysis. HA and JB drafted the manuscript and JB conceived the study and provided critical comments. All authors read and approved the final manuscript.

\section{Acknowledgements}

JB would like to acknowledge Discovery Grant funding from the Natural Sciences and Engineering Research Council of Canada (NSERC) (grant number 293295-2009) and Canadian Institutes of Health Research (CIHR) (grant number 84392). JB holds the John D. Cameron Endowed Chair in the Genetic Determinants of Chronic Diseases, Department of Clinical Epidemiology and Biostatistics, McMaster University. The GAW18 whole genome sequence data were provided by the T2D-GENES Consortium, which is supported by NIH grants U01 DK085524, U01 DK085584, U01 DK085501, U01 DK085526, and U01 DK085545. The other genetic and phenotypic data for GAW18 were provided by the San Antonio Family Heart Study and San Antonio Family Diabetes/Gallbladder Study, which are supported by NIH grants P01 HL045222, R01 DK047482, and R01 DK053889. The Genetic Analysis Workshop is supported by NIH grant R01 GM031575. We would like 
to thank two anonymous reviewers and the editor for insightful comments that improved the presentation and clarity of our manuscript.

This article has been published as part of BMC Proceedings Volume 8 Supplement 1, 2014: Genetic Analysis Workshop 18. The full contents of the supplement are available online at http://www.biomedcentral.com/bmcproc/ supplements/8/S1. Publication charges for this supplement were funded by the Texas Biomedical Research Institute.

\section{Authors' details}

'Statistics Department, King Abdulaziz University, Abdullah Sulayman, Jeddah 22254, Saudi Arabia. ${ }^{2}$ Mathematics and Statistics Department, McMaster University, Hamilton, Ontario, Canada. ${ }^{3}$ Population Genomics Program, Department of Clinical Epidemiology \& Biostatistics, McMaster University, Hamilton, Ontario, Canada.

Published: 17 June 2014

\section{References}

1. Levy D, Ehret GB, Rice K, Verwoert GC, Launer LJ, Dehghan A, Glazer NL, Morrison AC, Johnson AD, Aspelund T, et al: Genome-wide association study of blood pressure and hypertension. Nat Genet 2009, 41:677-687.

2. Lin Y, Lai X, Chen B, Xu Y, Huang B, Chen Z, Zhu S, Yao J, Jiang Q, Huang H, Wen J, Chen G: Genetic variations in CYP17A1, CACNB2 and PLEKHA7 are associated with blood pressure and/or hypertension in She ethnic minority of China. Atherosclerosis 2011, 219:709-714.

3. Adeyemo A, Gerry N, Chen G, Herbert A, Doumatey A, Huang H, Zhou J, Lashley K, Chen Y, Christman M, Rotimi C: A genome-wide association study of hypertension and blood pressure in African Americans. PLOS Genet 2009, 5:e1000564.

4. Wang K, Li M, Bucan M: Pathway-based approaches for analysis of genomewide association studies. Am J Hum Genet 2007, 81:1278-1283.

5. Beyene J, Hu P, Hamid J, Parkhomenko E, Paterson A, Tritchler D: Pathwaybased analysis of a genome-wide case-control association study of rheumatoid arthritis. BMC Proc 2009, 3(Suppl 7):S128.

6. Subramanian A, Tamayo P, Mootha VK, Mukherjee S, Ebert BL, Gillette MA, Paulovich A, Pomeroy SL, Golub TR, Lander ES, Mesirov JP: Gene set enrichment analysis: a knowledge-based approach for interpreting genome-wide expression profiles. Proc Natl Acad Sci U S A 2005, 102:15545-15550.

7. Mootha VK, Lindgren CM, Eriksson KF, Subramanian A, Sihag S, Lehar J, Puigserver P, Carlsson E, Ridderstråle M, Laurila E, et al: PGC-1a-responsive genes involved in oxidative phosphorylation are coordinately downregulated in human diabetes. Nat Genet 2003, 34:267-273.

8. Sha $Q$, Wang $X$, Wang $X$, Zhang S: Detecting association of rare and common variants by testing an optimally weighted combination of variants. Genet Epidemiol 2012, 36:561-571.

9. GSEA:Gene Set Enrichment Analysis. MSigDB. [http://www.broadinstitute. org/gsea/msigdb/collection_details.jpp\#C2].

10. Marsit CJ, Wiencke JK, Liu M, Kelsey KT: The race associated allele of Semaphorin 3B (SEMA3B) T415I and its role in lung cancer in AfricanAmericans and Latino-Americans. Carcinogenesis 2005, 26:1446-1449.

11. Joseph D, Ho SM, Syed V: Hormonal regulation and distinct functions of semaphorin-3B and semaphorin-3F in ovarian cancer. Mol Cancer Ther 2010, 9:499-509.

12. Isenberg JS, Qin Y, Maxhimer JB, Sipes JM, Despres D, Schnermann J, Frazier WA, Roberts DD: Thrombospondin-1 and CD47 regulate blood pressure and cardiac responses to vasoactive stress. Matrix Biol 2009, 28:110-119.

13. Bauer EM, Qin Y, Miller TW, Bandle RW, Csanyi G, Pagano PJ, Bauer PM, Schnermann J, Roberts DD, Isenberg JS: Thrombospondin-1 supports blood pressure by limiting eNOS activation and endothelial-dependent vasorelaxation. Cardiovasc Res 2010, 88:471-781.

doi:10.1186/1753-6561-8-S1-S101

Cite this article as: Alsulami et al:: Pathway-based analysis of rare and common variants to test for association with blood pressure. BMC Proceedings 2014 8(Suppl 1):S101.

\section{Submit your next manuscript to BioMed Central and take full advantage of:}

- Convenient online submission

- Thorough peer review

- No space constraints or color figure charges

- Immediate publication on acceptance

- Inclusion in PubMed, CAS, Scopus and Google Scholar

- Research which is freely available for redistribution

Submit your manuscript at www.biomedcentral.com/submit
C Biomed Central 